\title{
Is adherence to the 24-hour movement guidelines associated with a reduced risk of adiposity among children and adolescents?
}

\author{
Lukáš Jakubec ${ }^{1}$, Aleš Gába ${ }^{1 *}$ D, Jan Dygrýn', Lukáš Rubín,2, Adam Šimůnek and Erik Sigmund
}

\begin{abstract}
Background: Little is known about the combined effect of physical activity (PA), recreational screen time (ST), and sleep in preventing childhood obesity. Hence, this study aimed to analyze the associations between meeting the PA, ST, and sleep recommendations within the 24-hour movement guidelines and adiposity indicators among children and adolescents.
\end{abstract}

Methods: A total of 679 children and adolescents aged 8-18 years were included. The time spent in moderate-tovigorous PA and the sleep duration were estimated from raw data from a wrist-worn accelerometer. Recreational ST was reported by the child or parent. Body mass index (BMI) $z$-score, fat mass percentage (FM\%), and visceral adipose tissue (VAT) were used as adiposity indicators. Participants with $\geq 60 \mathrm{~min} /$ day of moderate-to-vigorous PA, $<2 \mathrm{~h} /$ day of recreational ST, and uninterrupted sleep for 9-11 h/day (for children) or 8-10 h/day (for adolescents) were considered to meet the overall 24-hour movement guidelines.

Results: Meeting the ST only recommendation was associated with reduced odds of a high BMI z-score (odds ratio $[O R]=0.38,95 \%$ confidence interval [Cl]: 0.17-0.89), excess FM\% (OR=0.34, 95\% Cl: 0.13-0.93), and excess VAT $(\mathrm{OR}=0.27,95 \% \mathrm{Cl}: 0.10-0.74)$ in adolescents. Significantly reduced odds of a high BMl z-score was associated with meeting the combination of the ST and sleep recommendations $(\mathrm{OR}=0.11,95 \% \mathrm{Cl}$ : $0.01-0.89)$. Adolescents who met one recommendation ( $\mathrm{OR}=0.51,95 \% \mathrm{Cl}: 0.27-0.96)$ or any two recommendations $(\mathrm{OR}=0.33,95 \% \mathrm{Cl}$ : $0.11-$ 0.94) had reduced ORs of having a high BMI $z$-score. Adolescents had lower odds of having excess VAT if they met one recommendation ( $\mathrm{OR}=0.39,95 \% \mathrm{Cl}: 0.19-0.81)$ or any two recommendations ( $\mathrm{OR}=0.25,95 \% \mathrm{Cl}: 0.07-0.90)$. No significant associations were found in children.

Conclusions: The present study showed no associations between meeting all three recommendations within the 24-hour movement guidelines and adiposity indicators. However, meeting ST only recommendation and the combination of the ST and sleep recommendations was associated with a reduced risk of excess adiposity. This finding should be considered when designing effective strategies and interventions to prevent childhood obesity.

Keywords: Accelerometry, Childhood obesity, Physical activity, Screen time, Sleep

\footnotetext{
* Correspondence: ales.gaba@upol.cz

${ }^{1}$ Faculty of Physical Culture, Palacký University Olomouc, trída Míru 117, 779 00 Olomouc, Czech Republic

Full list of author information is available at the end of the article
}

(c) The Author(s). 2020 Open Access This article is licensed under a Creative Commons Attribution 4.0 International License, which permits use, sharing, adaptation, distribution and reproduction in any medium or format, as long as you give appropriate credit to the original author(s) and the source, provide a link to the Creative Commons licence, and indicate if changes were made. The images or other third party material in this article are included in the article's Creative Commons licence, unless indicated otherwise in a credit line to the material. If material is not included in the article's Creative Commons licence and your intended use is not permitted by statutory regulation or exceeds the permitted use, you will need to obtain permission directly from the copyright holder. To view a copy of this licence, visit http://creativecommons.org/licenses/by/4.0/ The Creative Commons Public Domain Dedication waiver (http://creativecommons.org/publicdomain/zero/1.0/) applies to the data made available in this article, unless otherwise stated in a credit line to the data. 


\section{Background}

Obesity has become a major health challenge worldwide because its prevalence has substantially increased in the past four decades [1, 2]. Childhood obesity is significantly associated with an increased risk of incident severe obesity in adulthood [3, 4], as well as several noncommunicable diseases and all-cause mortality later in life [5]. Moreover, the severity of health consequences associated with obesity might be influenced by body fat distribution, especially with increasing visceral adipose tissue (VAT) levels [6]. Obesity also has a high economic burden. Member countries of the Organisation for Economic Co-operation and Development spend 331 billion US dollars annually to treat diseases caused by overweight and obesity, which is equal to $8.4 \%$ of the total health-care costs [7]. Thus, there is an urgent need to prevent overweight and obesity to save societal resources [8].

In the past decades, several global and national intervention strategies were developed to prevent the increasing levels of overweight and obesity in childhood. These strategies mainly focused on optimizing energy balance by changing the level of physical activity (PA) and/or by improving dietary patterns [9]. A previous study has shown that single-component interventions, including PA, may have an weak positive effect on weight loss [10]. This result may be attributed to the fact that interventions exclusively focused on moderate-to-vigorous physical activity (MVPA), which represents $<5 \%$ of the time in a 24-h period [11], while ignoring other movement behaviors. Excessive sedentary behavior (SB) and short sleep duration are also well-known contributors to the obesity risk [12, 13]. For this reason, all movement behaviors within the 24-h period should be considered for designing effective interventions to prevent childhood obesity.

On the basis of the understanding of the effects of human movement behaviors during the entire 24-h period on health [11], the first 24-hour movement guidelines for children and adolescents were developed and presented in Canada [14] in 2016. After 1 year, the guidelines for children aged $<5$ years were released [15]. Thereafter, Australia, New Zealand, South Africa, and the World Health Organization introduced the 24-hour movement guidelines for children in different age groups [16-20]. Unlike the previous guidelines, which mainly focused on the time spent in MVPA, the 24-hour movement guidelines incorporate sleep and recreational screen time (ST) recommendations.

The 24-hour movement guidelines were established to encourage children and adolescents to achieve optimal balance between different behaviors within a day and to prevent them from developing various non-communicable diseases including obesity. To date, only a few studies have analyzed the associations between meeting the 24-hour movement guidelines and adiposity indicators in the pediatric population [21, 22]. The main limitations of these studies were that all recommendations within the 24-hour movement guidelines were obtained from selfreport questionnaires [21] and that a narrow age group was investigated [22]. Hence, this cross-sectional study used device-measured PA and sleep, and self- or parentalreported recreational ST among children and adolescents to (1) examine the associations between adherence to the 24-hour movement guidelines and adiposity indicators, and (2) identify whether meeting different numbers and specific combinations within the 24-hour movement guidelines is associated with the adiposity status.

\section{Methods}

\section{Participants}

The study included children (age 8-13 years) and adolescents (age 14-18 years) who were recruited from seven elementary schools and four high schools in the Czech Republic. The parents or guardians of the participants received information leaflets about the complete description of the study after the school management approved the research. The main inclusion criteria were participant age and good health condition, which was reported by their parents. Those participants whose parents reported medical complications that could affect PA and sleep were excluded from study. The sample comprised 907 children and adolescents who agreed to participate. However, approximately $25 \%$ of the participants were excluded because they voluntarily withdrew from the study or became ill $(n=45)$, provided incomplete data $(n=129)$, had data that could not be assessed because of technical failures $(n=17)$, or did not meet the criteria for accelerometer wear time $(n=37)$. Therefore, the final sample comprised 679 participants (57\% girls) who provided complete data. The characteristics of the participants are shown in Table 1.

\section{Procedure}

Data collection was conducted during the spring and fall seasons between March 2018 and April 2019. Monitoring was performed during weeks with a regular school schedule. The participants in each school were visited twice. During the first visit, accelerometers, daily logs, and questionnaires were distributed. The participants were instructed on how to wear the accelerometer and how to properly enter data in the daily log. Assessment of adiposity was also performed. Accelerometer monitoring was started in the midnight after the initial visit. Thus, the participants were instructed to wear the device before bedtime. The second visit was conducted 8 days after the initial visit, and the accelerometers, daily logs, and filled questionnaires were collected. 
Table 1 Descriptive characteristics and weight status of the study sample

\begin{tabular}{|c|c|c|c|c|c|c|c|}
\hline & \multicolumn{2}{|c|}{$\begin{array}{l}\text { Total } \\
\boldsymbol{N}=679\end{array}$} & \multicolumn{2}{|c|}{$\begin{array}{l}\text { Children } \\
\boldsymbol{n}=355\end{array}$} & \multicolumn{2}{|c|}{$\begin{array}{l}\text { Adolescents } \\
\boldsymbol{n}=324\end{array}$} & \multirow[t]{2}{*}{$\boldsymbol{p}$-value } \\
\hline & Mean & SD & Mean & SD & Mean & SD & \\
\hline Age (years) & 13.9 & 2.8 & 11.7 & 1.6 & 16.3 & 1.3 & $<0.001$ \\
\hline Height (cm) & 160.5 & 14.1 & 151.6 & 12.0 & 170.2 & 8.8 & $<0.001$ \\
\hline Weight (kg) & 52.9 & 15.0 & 43.6 & 11.3 & 63.0 & 11.6 & $<0.001$ \\
\hline BMI z-score & 0.22 & 1.06 & 0.24 & 1.13 & 0.20 & 0.99 & 0.587 \\
\hline Fat mass (\%) & 20.0 & 8.7 & 19.3 & 8.3 & 20.7 & 9.1 & 0.035 \\
\hline Visceral adipose tissue $\left(\mathrm{cm}^{2}\right)$ & 48.5 & 31.1 & 42.7 & 28.1 & 54.9 & 32.9 & $<0.001$ \\
\hline \multicolumn{8}{|l|}{ Weight status ${ }^{a}$ (\% of $n$ ) } \\
\hline Underweight & 1.3 & & 2.0 & & 0.6 & & 0.112 \\
\hline Normal weight & 76.3 & & 73.5 & & 79.3 & & 0.076 \\
\hline Overweight & 17.1 & & 17.2 & & 17.0 & & 0.945 \\
\hline Obese & 5.3 & & 7.3 & & 3.1 & & 0.015 \\
\hline MVPA (min/day) ${ }^{b}$ & 49.1 & 23.9 & 58.1 & 24.3 & 39.3 & 19.1 & $<0.001$ \\
\hline ST (h/day) & 3.0 & 2.0 & 3.0 & 1.8 & 2.8 & 2.1 & 0.206 \\
\hline $\mathrm{SL}(\mathrm{h} / \text { day })^{\mathrm{b}}$ & 8.1 & 0.9 & 8.6 & 0.7 & 7.5 & 0.8 & $<0.001$ \\
\hline
\end{tabular}

BMI - body mass index, MVPA - moderate-to-vigorous physical activity, ST - screen time, SL - sleep

aased on the BMI $z$-score

${ }^{\mathrm{b}}$ Adjusted to $24 \mathrm{~h}$

'The differences between age categories were analyzed with the independent $t$-test for continuous variables and the chi-square test for categorical variables

\section{Physical activity and sleep}

PA and sleep were measured using ActiGraph tri-axial accelerometers (ActiGraph, Pensacola, FL, USA), including wGT3X-BT and GT9X Link for children and adolescents, respectively. Both scientific-grade accelerometers are commonly used in the PA [23-25] and sleep [26, 27] research and provide reliable and valid measures [28-30]. The participants wore the accelerometer on the non-dominant wrist for $24 \mathrm{~h} /$ day for 7 consecutive days, except when bathing, swimming, and performing personal hygiene. These non-wear windows were recorded into the provided daily log together with the participants' wake-up and fallasleep time. In participants $<12$ years old (i.e., those in the first stage of elementary school), assistance from the parent or teacher was needed to obtain the precise time when filling the daily log.

The accelerometers were initialized to collect acceleration data on three axes at a sampling rate of $100 \mathrm{~Hz}$ and were downloaded using ActiLife software version 6.13.3 (ActiGraph Corp., Pensacola, FL, USA). Data were saved as GT3X files before they were converted to the raw .csv file format. The open-source $R$ package GGIR version 1.10-7 (https://cran.r-project.org/web/packages/ GGIR/) was used to calculate the Euclidean Norm Minus One metric, with negative values rounded up to zero [31]. The time spent in MVPA was calculated without bout criteria using the $>201 \mathrm{mg}$ threshold proposed by Hildebrand et al. [32]. The heuristic algorithm [33] guided by individual wake-up and fall-asleep times from the daily log was used to identify the sleep time. The day cycle was determined using the "from waking up to waking up the next day" approach, which means that a full night of sleep is included in a day cycle and that the duration of a day cycle may vary. Participants were excluded if they had fewer than three weekdays and one weekend day of valid wear (defined as $\geq 16 \mathrm{~h}$ per day), or if wear data for each $15-\mathrm{min}$ period in the 24-h cycle were not available [34].

\section{Screen time}

Recreational ST on weekdays and weekend days was obtained using the following questions from the Health Behaviour in School-aged Children study [35]: "About how many hours a day do you usually spend watching television, DVDs, videos (including YouTube or similar online service) in your free time on weekdays (weekend days)?" and "About how many hours a day do you usually spend playing games on a computer, games console (PlayStation, Xbox, etc.), smartphone, tablet, or similar electronic device in your free time on weekdays (weekend days)?" Nine response options were provided for each question $(0,0.5,1,2,3,4,5,6$, and $\geq 7 \mathrm{~h} /$ day $)$. The validity and reliability of the questions for the past 7 days has been proved in comparison with the 7-day 24-h diaries both on weekdays and at weekends [36].

A parent proxy report was required in children aged $\leq 12$ years. In total, 16 (3\%) participants had missing data for one or two ST items. The expectation-maximization algorithm was used to impute missing data. Those with missing items (three or all) were excluded from the 
analysis. The total ST was calculated by obtaining the sum of the weighted averages of ST during weekdays and weekends (weighted average $=$ [average of weekdays $\cdot 5+$ average of weekend days $\cdot 2] / 7)$.

\section{Adherence to the 24-hour movement guidelines}

Participants with $\geq 60 \mathrm{~min} /$ day of MVPA, $<2 \mathrm{~h} /$ day of recreational ST, and uninterrupted sleep for 9-11 h/day (for children) or 8-10 h/day (for adolescents) were considered to meet the overall 24-hour movement guidelines [14].

\section{Adiposity indicators}

Body mass index (BMI) $z$-score, fat mass percentage (FM\%), and VAT were used as the indicators of adiposity. To calculate BMI, the height and weight of the participants were measured using a standard procedure with an accuracy of $0.1 \mathrm{~cm}$ and $0.1 \mathrm{~kg}$, respectively. Sex- and age-specific BMI cutoff points were used to identify participants with overweight and obesity (i.e., BMI $z$-score $>1$ standard deviation $[\mathrm{SD}])$.

The total and visceral adiposity levels were measured using the InBody 720 device (InBody Co., Seoul, Korea), which is a multi-frequency bioimpedance analyzer used to measure resistance in broadband frequencies $(1-1000$ $\mathrm{kHz}$ ) and reactance in mean frequencies $(5-250 \mathrm{kHz})$. Bioimpedance analysis is considered suitable for assessing adiposity in a target population, as its validity has been confirmed [37]. The participants were instructed in advance to maintain proper hydration, avoid any vigorous exercise for at least 1 day before the examination, and fast at least $4 \mathrm{~h}$ before the examination. Assessment of adiposity was performed on school premises during school hours (8:00-13:30). Excess adiposity was defined as the sex- and age-specific 85th percentile of FM\% and VAT.

\section{Potential confounding variables}

We selected possible confounding factors that were available in the dataset and have been shown to be associated with adiposity indicators. Maternal obesity was based on BMI calculated from self-reported height and weight. Unhealthy diet was characterized by a high frequency of fast-food consumption (i.e., $\geq 1$ portion per a week), and data about this diet were obtained using a single-item question. Maternal obesity and unhealthy diet have been dichotomized before analysis. Birth weight and maternal height and weight were reported by the parents. The parent-reported data of unhealthy diet were required only in children $<12$ years old (i.e., those in the first stage of elementary school). The school location was also considered as the participants were recruited within clusters. However, the school location was not included in the final models as this potential confounder was not associated with the outcome variable and its omission did not reduce the overall significance of the regression models.

\section{Statistical analysis}

All statistical analyses were conducted using the Statistical Package for the Social Sciences software version 25 (IBM Company, Armonk, NY, USA). The descriptive statistics of the outcome measures are presented as mean and SD. The differences between age groups were analyzed with the independent $t$-test for continuous variables and with the chi-square test for categorical variables.

A binary logistic regression analysis was performed to estimate the odds of excess adiposity in participants who met different numbers and combinations of recommendations within the 24-hour movement guidelines. Analysis was performed using two separate regression models. In the first model, odds ratios (ORs) with 95\% confidence intervals (CIs) of having excess adiposity were calculated for those who met one, any two, or all three recommendations. In the second model, the ORs for all possible combinations within the 24-hour movement guidelines (i.e., eight categories) were calculated. Participants who did not meet any recommendation were used as the reference group in all analyses. The estimates were based on logistic regression models adjusted for sex, age, and confounding factors. The level of significance was set at $p<0.05$.

\section{Results}

The characteristics of the participants are shown in Table 1 . The mean age of the total sample was $13.9 \pm$ 2.8 years, and $22.4 \%$ of the participants were overweight and obese. The FM\% and VAT of adolescents were significantly higher than those of children, by $1.4 \%(p=0.035)$ and $12.2 \mathrm{~cm}^{2}(p<0.001)$, respectively. Although the prevalence of overweight was almost equal between age groups, the prevalence of obesity was more than two-fold lower in adolescents than in children $(p=0.015)$. The MVPA and ST of adolescents were lower by $18.8 \mathrm{~min} /$ day $(p<0.001)$ and $1.1 \mathrm{~h} /$ day $(p<0.001)$, respectively, than those of the children. None of the participants had longer sleep duration as it is recommended.

Only $6.5 \%$ of children (Table 2 ) and $2.2 \%$ of adolescents (Table 3) met all 3 recommendations. Adolescents who met only one recommendation had lower odds of having a high BMI $z$-score (OR $=0.51,95 \%$ CI: $0.27-0.96)$ and excess VAT $(\mathrm{OR}=0.39,95 \% \mathrm{CI}$ : $0.19-0.81)$ than those who did not meet any recommendation. Furthermore, meeting any two recommendations was associated with lower odds of having 
Table 2 Odds of excess adiposity in children who met different numbers and specific combinations of recommendations within the 24-hour movement guidelines $(n=355)$

\begin{tabular}{|c|c|c|c|c|c|c|c|c|c|c|}
\hline & \multirow{2}{*}{$\begin{array}{l}\text { Adherence } \\
\%\end{array}$} & \multicolumn{3}{|c|}{ BMl $\boldsymbol{z}$-score > 1 SD } & \multicolumn{3}{|c|}{$>85$ th percentile of FM\% } & \multicolumn{3}{|c|}{$>85$ th percentile of VAT } \\
\hline & & $\mathrm{OR}$ & $(95 \% \mathrm{Cl})$ & $\boldsymbol{p}$-value & $\mathrm{OR}$ & $(95 \% \mathrm{Cl})$ & $\boldsymbol{p}$-value & $\mathrm{OR}$ & $(95 \% \mathrm{Cl})$ & $p$-value \\
\hline \multicolumn{11}{|l|}{ Number of recommendations } \\
\hline None & 33.0 & Ref. & & & Ref. & & & Ref. & & \\
\hline One & 37.7 & 1.44 & $(0.79-2.61)$ & 0.234 & 1.05 & $(0.53-2.10)$ & 0.891 & 1.05 & $(0.52-2.11)$ & 0.898 \\
\hline Two & 22.8 & 1.05 & $(0.51-2.15)$ & 0.901 & 0.52 & $(0.20-1.33)$ & 0.171 & 0.46 & $(0.17-1.23)$ & 0.121 \\
\hline Three & 6.5 & 0.33 & $(0.07-1.54)$ & 0.158 & 0.25 & $(0.31-1.93)$ & 0.187 & 0.26 & $(0.03-2.05)$ & 0.199 \\
\hline \multicolumn{11}{|l|}{ Combinations of recommendations } \\
\hline Did not meet any recommendation & 33.0 & Ref. & & & Ref. & & & Ref. & & \\
\hline PA only & 18.3 & 1.66 & $(0.81-3.39)$ & 0.165 & 0.94 & $(0.40-2.24)$ & 0.889 & 1.09 & $(0.46-2.57)$ & 0.849 \\
\hline ST only & 11.0 & 1.06 & $(0.43-2.62)$ & 0.907 & 1.08 & $(0.40-2.90)$ & 0.887 & 0.69 & $(0.23-2.12)$ & 0.519 \\
\hline SL only & 8.4 & 1.52 & $(0.59-3.94)$ & 0.387 & 1.29 & $(0.43-3.90)$ & 0.647 & 1.54 & $(0.53-4.46)$ & 0.425 \\
\hline $\mathrm{PA}+\mathrm{ST}$ & 8.2 & 0.84 & $(0.28-2.54)$ & 0.761 & 0.42 & $(0.09-1.95)$ & 0.267 & 0.42 & $(0.09-1.99)$ & 0.275 \\
\hline$P A+S L$ & 9.3 & 1.16 & $(0.45-3.00)$ & 0.755 & 0.73 & $(0.22-2.38)$ & 0.600 & 0.54 & $(0.15-2.05)$ & 0.368 \\
\hline $\mathrm{ST}+\mathrm{SL}$ & 5.3 & 1.13 & $(0.34-3.78)$ & 0.837 & 0.32 & $(0.04-2.58)$ & 0.285 & 0.34 & $(0.04-2.75)$ & 0.312 \\
\hline$P A+S T+S L$ & 6.5 & 0.34 & $(0.07-1.56)$ & 0.163 & 0.25 & $(0.03-1.97)$ & 0.187 & 0.26 & $(0.03-2.07)$ & 0.202 \\
\hline
\end{tabular}

BMI - body mass index, Cl - confidence interval, FM\% - fat mass percentage, OR - odds ratio, PA - physical activity, Ref - reference group, SD - standard deviation, ST - screen time, SL - sleep, VAT - visceral adiposity tissue

The model was adjusted for sex, age, birth weight, maternal obesity, and unhealthy diet

Children with $\geq 60 \mathrm{~min} /$ day of moderate-to-vigorous physical activity, $<2 \mathrm{~h} /$ day of recreational ST, and uninterrupted sleep for 9-11 h/day were considered to meet the overall 24-hour movement guidelines

Table 3 Odds of excess adiposity in adolescents who met different numbers and specific combinations of recommendations within the 24-hour movement guidelines $(n=324)$

\begin{tabular}{|c|c|c|c|c|c|c|c|c|c|c|}
\hline & \multirow{2}{*}{$\begin{array}{l}\text { Adherence } \\
\%\end{array}$} & \multicolumn{3}{|c|}{ BMI $\boldsymbol{z}$-score $>1$ SD } & \multicolumn{3}{|c|}{$>85$ th percentile of FM\% } & \multicolumn{3}{|c|}{$>85$ th percentile of VAT } \\
\hline & & $\overline{\mathrm{OR}}$ & $(95 \% \mathrm{Cl})$ & $\overline{\boldsymbol{p} \text {-value }}$ & $\overline{\mathrm{OR}}$ & $(95 \% \mathrm{Cl})$ & $\overline{p \text {-value }}$ & $\overline{\mathrm{OR}}$ & $(95 \% \mathrm{Cl})$ & $\overline{\boldsymbol{p} \text {-value }}$ \\
\hline \multicolumn{11}{|l|}{ Number of recommendations } \\
\hline None & 36.4 & Ref. & & & Ref. & & & Ref. & & \\
\hline One & 47.2 & 0.51 & $(0.27-0.96)$ & 0.042 & 0.49 & $(0.23-1.03)$ & 0.059 & 0.39 & $(0.19-0.81)$ & 0.012 \\
\hline Two & 14.2 & 0.33 & $(0.11-0.94)$ & 0.039 & 0.69 & $(0.25-1.88)$ & 0.468 & 0.25 & $(0.07-0.90)$ & 0.034 \\
\hline Three & 2.2 & 1.27 & $(0.23-7.16)$ & 0.787 & 0.77 & $(0.09-6.95)$ & 0.813 & 0.25 & $(0.07-5.88)$ & 0.704 \\
\hline \multicolumn{11}{|l|}{ Combinations of recommendations } \\
\hline Did not meet any recommendation & 36.4 & Ref. & & & Ref. & & & Ref. & & \\
\hline PA only & 6.8 & 0.67 & $(0.20-2.22)$ & 0.510 & 0.23 & $(0.03-1.79)$ & 0.158 & 0.18 & $(0.02-1.39)$ & 0.100 \\
\hline ST only & 26.2 & 0.38 & $(0.17-0.89)$ & 0.025 & 0.34 & $(0.13-0.93)$ & 0.035 & 0.27 & $(0.10-0.74)$ & 0.010 \\
\hline SL only & 14.2 & 0.63 & $(0.26-1.57)$ & 0.325 & 0.90 & $(0.34-2.34)$ & 0.824 & 0,72 & $(0.28-1.86)$ & 0.500 \\
\hline $\mathrm{PA}+\mathrm{ST}$ & 4.9 & 0.34 & $(0.07-1.65)$ & 0.179 & 0.59 & $(0.12-2.88)$ & 0.514 & 0.22 & $(0.03-1.79)$ & 0.157 \\
\hline$P A+S L$ & 2.5 & 1.56 & $(0.27-8.85)$ & 0.618 & 2.15 & $(0.38-12.23)$ & 0.387 & 1.79 & $(0.32-10.10)$ & 0.510 \\
\hline $\mathrm{ST}+\mathrm{SL}$ & 6.8 & 0.11 & $(0.01-0.89)$ & 0.039 & 0.42 & $(0.09-2.01)$ & 0.281 & NA & & \\
\hline $\mathrm{PA}+\mathrm{ST}+\mathrm{SL}$ & 2.2 & 1.20 & $(0.21-6.79)$ & 0.836 & 0.72 & $(0.08-6.58)$ & 0.774 & 0.62 & $(0.07-5.59)$ & 0.668 \\
\hline
\end{tabular}

BMI - body mass index, $\mathrm{Cl}$ - confidence interval, FM\% - fat mass percentage, OR - odds ratio, PA - physical activity, Ref - reference group, SD - standard deviation, ST - screen time, SL - sleep, VAT - visceral adiposity tissue NA, not applicable - indicating insufficient sample size for estimation The model was adjusted for sex, age, birth weight, maternal obesity, and unhealthy diet Adolescents with $\geq 60 \mathrm{~min} /$ day of moderate-to-vigorous physical activity, $<2 \mathrm{~h} /$ day of recreational ST, and uninterrupted sleep for $8-10 \mathrm{~h} /$ day were considered to meet the overall 24-hour movement guidelines 
a high BMI $z$-score $(\mathrm{OR}=0.33,95 \% \mathrm{CI}$ : 0.11-0.94) and excess VAT (OR $=0.25,95 \%$ CI: 0.07-0.90).

The results presented in Tables 2 and 3 show that adolescents who met the ST only recommendation had significantly lower odds of having excess adiposity, which was defined by BMI $z$-score $(\mathrm{OR}=0.38,95 \% \mathrm{CI}$ : $0.17-0.89)$, FM\% (OR $=0.34,95 \%$ CI: $0.13-0.93)$, and VAT $(\mathrm{OR}=0.27,95 \% \mathrm{CI}: 0.10-0.74)$ compared with those who did not meet any recommendation. Moreover, significantly lower odds of having a high BMI $z$-score $(\mathrm{OR}=0.11,95 \% \mathrm{CI}: 0.01-0.89)$ was observed in adolescents when the combination of ST and sleep recommendations was met. No significant associations were found in children.

\section{Discussion}

This study revealed that a low proportion of children and adolescents met all three recommendations within the 24-hour movement guidelines. Meeting one recommendation or any two recommendations within the 24hour movement guidelines was associated with a reduced risk of excess adiposity in adolescents. Specifically, ORs for excess adiposity were significantly lower when adolescents met the ST only recommendation and the combination of the ST and sleep recommendations. No significant associations were found in children.

Surprisingly, the present study showed no associations between meeting all three recommendations within the 24-hour movement guidelines and adiposity indicators. This finding is in contrast to other published studies reporting that a favorable adiposity status is associated with meeting more recommendations [21, 22]. The same trend was also found for several cardiometabolic markers and physical fitness [38]. One possible explanation for such finding may be the very low adherence to all three recommendations in our sample. Therefore, the results of the analysis should be interpreted with caution because the used regression models rely on asymptotics.

The results of the present study suggest that reducing the time spent in front of a screen could be a potential target for preventing childhood obesity. Our findings are in accordance with previously published studies reporting that meeting the ST recommendation is associated with lower odds of obesity whether or not PA and sleep recommendations are met [22, 39]. It can be assumed that ST, a main contributor to the total SB, accumulates with a few prolonged uninterrupted sedentary periods, which are associated with excess adiposity independently of PA [40].

Our study extends the existing literature by showing that participants who met the combination of ST and sleep recommendations had lower odds of having a high BMI $z$-score. This finding could be attributable to the compensatory change between 24-hour movement behaviors that are typical examples of compositional data [41]. We can therefore hypothesize that a decrease in the time spent in front of a screen leads to an increase in the remaining behaviors within the 24-h period, especially to an increase in sleep duration. The study by Lin et al. [42] supported this assumption by showing that a lower amount of time spent in SB is associated with a higher sleep duration in the subsequent night. This relationship seems to be bidirectional, as an association between sleep duration and SB in the following day was also confirmed. Thus, intervention programs targeting ST reduction and improving sleep duration are warranted to reduce the increasing prevalence of childhood obesity.

Another original finding was that our analysis confirmed associations only in adolescents but not in children. This finding could be explained by a decrease in family influence (i.e., parental modeling and encouragement, household rules, and restrictions) with respect to health behaviors during the transition from childhood to adolescence [43]. It can be assumed that adolescents are less restricted by parents in terms of ST than children. Adolescents also have higher bedtime autonomy, which is associated with a short sleep duration [44]. Moreover, this relationship is moderated by overuse of electronic devices before going to sleep. In addition to the fact that extensive ST and lack of sleep are significant contributors to childhood obesity, such behaviors are also related to other obesogenic behaviors, such as unhealthy eating [45]. For this reason, adolescents who meet the ST and sleep recommendations are probably less exposed to other obesogenic behaviors than children, and therefore have higher odds of having a favorable adiposity status. Future research should verify this hypothesis, as this is beyond the scope of the present study.

The major strength of the present study was using the 24-h multi-day raw accelerometer data in assessing PA and sleep. Another strength is that the research sample was not limited to a narrow age group, as in previous studies [22]. Finally, the inclusion of demographic and behavioral measures allowed us to adjust the regression models for several confounding factors.

This study had some limitations. First, the design was cross-sectional, which limits causal inferences between the adherence to the 24-hour movement guidelines and the adiposity status. Second, although the study participants were recruited from Czech cities of different sizes, the study sample was not fully representative because it mainly represents the urban population. Thus, the potential of our findings to be generalized to the rural population may be limited. Third, the estimated amount of time spent in MVPA may be biased in adolescents as the cut-off point (i.e., $201 \mathrm{mg}$ ) was proposed for children. Fourth, the determination of self- or parental-reported 
ST may be difficult, as multi-tasking has become a common phenomenon in adolescents [46] and this behavior is typically underreported [47]. Finally, considering that whole-body bioimpedance analysis is not considered a gold standard method for assessing VAT, the results of this analysis could be biased [48].

\section{Conclusions}

The present study showed no associations between meeting all three recommendations within the 24-hour movement guidelines and adiposity indicators. However, meeting the ST only recommendation or the combination of the ST and sleep recommendations was associated with a favorable adiposity status. Therefore, the combined effect of ST and sleep should be considered in establishing effective intervention strategies that target the prevention of childhood obesity.

\section{Abbreviations}

PA: Physical activity; MVPA: Moderate-to-vigorous physical activity SB: Sedentary behavior; ST: Recreational screen time; BMI: Body mass index; FM\%: Fat mass percentage; VAT: Visceral adipose tissue; SD: Standard deviation; OR: Odds radio; Cl: Confidence interval

\section{Acknowledgments}

The authors are grateful to the management of all participating schools and to all participants of this study.

\section{Authors' contributions}

$L J$ and $A G$ were responsible for the concept and design of the study. LJ, AG, $J D, L R$, and $A \breve{S}$ performed data collection and prepared the final dataset. AG and $L J$ conducted statistical analysis and provided editing assistance for tables and content. $L J, A G$, and $E S$ contributed to the interpretation of data. $L$ and $A G$ wrote the manuscript. JD, LR, AŠ, and ES were the major contributors in revising the manuscript. All authors critically reviewed the manuscript and approved the final version.

\section{Funding}

This research was funded by a research grant from the Czech Science Foundation (18-09188S) and by the Internal Grant Agency of Palacký University Olomouc (IGA_FTK_2018_001).

\section{Availability of data and materials}

The dataset analyzed during the current study is available in the Figshare repository, https://doi.org/10.6084/m9.figshare.12017886.

\section{Ethics approval and consent to participate}

All parents or guardians provided written consent for the participation of their children in the research. The study was approved by the Institutional Research Ethics Committee at the Faculty of Physical Culture of Palacký University Olomouc (reference no. 19/2017) and was conducted in accordance with the ethical standards of the 1964 Declaration of Helsinki and their official amendments.

\section{Consent for publication}

Not applicable.

\section{Competing interests}

The authors declare that they have no competing interests.

\section{Author details}

${ }^{1}$ Faculty of Physical Culture, Palacký University Olomouc, třída Míru 117, 779 00 Olomouc, Czech Republic. ${ }^{2}$ Faculty of Science, Humanities and Education, Technical University of Liberec, Liberec, Czech Republic.
Received: 24 March 2020 Accepted: 5 July 2020

Published online: 16 July 2020

\section{References}

1. Ng M, Fleming T, Robinson M, Thomson B, Graetz N, Margono C, et al. Global, regional, and national prevalence of overweight and obesity in children and adults during 1980-2013: a systematic analysis for the global burden of disease study 2013. Lancet. 2014;384(9945):766-81.

2. NCD Risk Factor Collaboration. Worldwide trends in body-mass index underweight, overweight, and obesity from 1975 to 2016: a pooled analysis of 2416 population-based measurement studies in 128.9 million children, adolescents, and adults. Lancet. 2017 Dec 16;390(10113):2627-42.

3. The NS, Suchindran C, North KE, Popkin BM, Gordon-Larsen P. Association of adolescent obesity with risk of severe obesity in adulthood. JAMA. 2010 Nov 10:304(18):2042-7.

4. $\quad$ Singh AS, Mulder C, Twisk JWR, Van Mechelen W, Chinapaw MJM. Tracking of childhood overweight into adulthood: a systematic review of the literature. Obes Rev. 2008 Sep 1;9(5):474-88.

5. Flegal KM, Graubard BI, Williamson DF, Gail MH. Cause-specific excess deaths associated with underweight, overweight, and obesity. JAMA. 2007 Nov 7;298(17):2028-37

6. Jensen MD. Health consequences of fat distribution. Hormones. 1997; 48(Suppl. 5):88-92

7. OECD. The heavy burden of obesity: the economics of prevention. Paris: OECD Publishing; 2019. 240 p.

8. Tremmel M, Gerdtham U-G, Nilsson PM, Saha S. Economic burden of obesity: a systematic literature review. Int J Environ Res Public Health. 2017 Apr 19;14(4):435.

9. Beets MW, Brazendale K, Weaver RG, Armstrong B. Rethinking behavioral approaches to compliment biological advances to understand the etiology, prevention, and treatment of childhood obesity. Child Obes. 2019 May 29; 15(6):353-8

10. Brown T, Moore THM, Hooper L, Gao Y, Zayegh A, ljaz S, et al. Interventions for preventing obesity in children. Cochrane Database Syst Rev. 2019;7:1-640.

11. Chaput J-P, Carson V, Gray CE, Tremblay MS. Importance of all movement behaviors in a 24 hour period for overall health. Int J Env Res Public Heal. 2014:11(12):12575-81.

12. Tremblay MS, LeBlanc AG, Kho ME, Saunders TJ, Larouche R, Colley RC, et al. Systematic review of sedentary behaviour and health indicators in schoolaged children and youth. Int J Behav Nutr Phys Act. 2011;8(1):98.

13. Cappuccio FP, Taggart FM, Kandala N-B, Currie A, Peile E, Stranges S, et al. Meta-analysis of short sleep duration and obesity in children and adults. Sleep. 2008;31(5):619-26

14. Tremblay MS, Carson V, Chaput J-P, Connor Gorber S, Dinh T, Duggan M, et al. Canadian 24-Hour Movement Guidelines for Children and Youth: An integration of physical activity, sedentary behaviour, and sleep. Appl Physiol Nutr Metab. 2016 Jun 1;41(6 (Suppl. 3)):S311-27.

15. Tremblay MS, Chaput J-P, Adamo KB, Aubert S, Barnes JD, Choquette L, et al. Canadian 24-hour movement guidelines for the early years ( $0-4$ years): an integration of physical activity, sedentary behaviour, and sleep. BMC Public Health. 2017;17(5):874.

16. WHO. Guidelines on physical activity, sedentary behaviour and sleep for children under 5 years of age. Geneva: World Health Organization; 2019. 22 p.

17. Ministry of Health. Sit less, move more, sleep well active play guidelines for under-fives. Wellington: Ministry of Health; 2017. 28 p.

18. Australian Government Department of Health. Australian 24-hour movement guidelines for children and young people (5-17 years) - an integration of physical activity, sedentary behaviour and sleep. Canberra: Department of Health; 2018. 149 p.

19. Australian Government Department of Health. Australian 24-hour movement guidelines for the early years (birth to 5 years): an integration of physical activity, sedentary behaviour, and sleep. Canberra: Department of Health; 2017. 2 p.

20. Draper CE, Tomaz SA, Biersteker L, Cook CJ, Couper J, de Milander M, et al. The south African 24-hour movement guidelines for birth to 5 years: an integration of physical activity, sitting behavior, screen time, and sleep. $J$ Phys Act Heal [Internet] 2020;17(1):109-119. Available from: https://journals. humankinetics.com/view/journals/jpah/17/1/article-p109.xml.

21. Katzmarzyk PT, Staiano AE. Relationship between Meeting 24-Hour Movement Guidelines and cardiometabolic risk factors in children. J Phys Act Health. 2017/09/13. 2017 Oct 1;14(10):779-84. 
22. Roman-Viñas B, Chaput J-P, Katzmarzyk PT, Fogelholm M, Lambert EV,

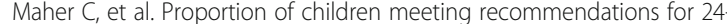
hour movement guidelines and associations with adiposity in a 12-country study. Int J Behav Nutr Phys Act. 2016;13(1):123.

23. Torres-Lopez L V, Cadenas-Sanchez C, Migueles JH, Adelantado-Renau M, Plaza-Florido A, Solis-Urra P, et al. Associations of sedentary behaviour, physical activity, cardiorespiratory fitness and body composition with risk of sleep-related breathing disorders in children with overweight/obesity: A cross-sectional study. J Clin Med 2020;9(1544).

24. McLellan G, Arthur R, Donnelly S, Buchan DS. Segmented sedentary time and physical activity patterns throughout the week from wrist-worn ActiGraph GT3X+ accelerometers among children 7-12 years old. J Sport Heal Sci. 2020;9(2):179-88.

25. Fairclough SJ, Taylor S, Rowlands AV, Boddy LM, Noonan RJ. Average acceleration and intensity gradient of primary school children and associations with indicators of health and well-being. J Sports Sci. 2019; 37(18):2159-67.

26. Brazendale K, Beets MW, Weaver RG, Perry MW, Tyler EB, Hunt ET, et al. Comparing measures of free-living sleep in school-aged children. Sleep Med. 2019;60:197-201

27. Adelantado-Renau M, Beltran-Valls MR, Migueles JH, Artero EG, Legaz-Arrese A, Capdevila-Seder A, et al. Associations between objectively measured and self-reported sleep with academic and cognitive performance in adolescents: DADOS study. J Sleep Res. 2019 Aug 1;28(4):e12811.

28. Crouter SE, Flynn Jl, Bassett DR Jr. Estimating physical activity in youth using a wrist accelerometer. Med Sci Sports Exerc. 2015;47(5):944-51.

29. Sadeh A, Acebo C. The role of actigraphy in sleep medicine. Sleep Med Rev. 2002:6(2):113-24.

30. Ryan N, Borg D, Fowler P, Osborne J, Stewart I, Pavey T, et al. Inter-device reliability of a wrist actigraph device in classifying sleep characteristics. J Sci Med Sport. 2019;22:S106.

31. Migueles JH, Rowlands AV, Huber F, Sabia S, van Hees VT. GGIR: a research community-driven open source $R$ package for generating physical activity and sleep outcomes from multi-day raw accelerometer data. J Meas Phys Behav. 2019;2(3):188-96.

32. Hildebrand $M$, van Hees VT. Hansen BHe, Ekelund U. age group comparability of raw accelerometer output from wrist- and hip-worn monitors. Med Sci Sport Exerc. 2014;46(9):1816-24.

33. van Hees VT, Sabia S, Anderson KN, Denton SJ, Oliver J, Catt M, et al. A novel, open access method to assess sleep duration using a wrist-worn accelerometer. PLoS One. 2015 Nov 16;10(11):e0142533.

34. Ricardo LIC, Wendt A, Galliano LM, de Andrade MW, Niño Cruz GI, Wehrmeister $F$, et al. Number of days required to estimate physical activity constructs objectively measured in different age groups: findings from three Brazilian (Pelotas) population-based birth cohorts. PLoS One. 2020;15(1): e0216017.

35. Currie C, Nic Gabhainn S, Godeau E. Committee the IHNC. The health behaviour in school-aged children: WHO collaborative cross-national (HBSC) study: origins, concept, history and development 1982-2008. Int J Public Health. 2009;54(2):131-9.

36. Schmitz KH, Harnack L, Fulton JE, Jacobs DR Jr, Gao S, Lytle LA, et al. Reliability and validity of a brief questionnaire to assess television viewing and computer use by middle school children. J Sch Health. 2004;74(9):370-7.

37. Lim JS, Hwang JS, Lee JA, Kim DH, Park KD, Jeong JS, et al. Crosscalibration of multi-frequency bioelectrical impedance analysis with eight-point tactile electrodes and dual-energy X-ray absorptiometry for assessment of body composition in healthy children aged 6-18 years. Pediatr Int. 2009;51(2):263-8.

38. Carson V, Chaput J-P, Janssen I, Tremblay MS. Health associations with meeting new 24-hour movement guidelines for Canadian children and youth. Prev Med (Baltim). 2017;95:7-13.

39. Laurson KR, Lee JA, Eisenmann JC. The cumulative impact of physical activity, sleep duration, and television time on adolescent obesity: 2011 youth risk behavior survey. J Phys Act Health. 2015;12(3):355-60.

40. Gába A, Pedišić Ž, Štefelová N, Dygrýn J, Hron K, Dumuid D, et al. Sedentary behavior patterns and adiposity in children: a study based on compositional data analysis. BMC Pediatr. 2020;20(1):147.

41. Pedišić Ž, Dumuid D, Olds TS. Integrating sleep, sedentary behaviour, and physical activity research in the emerging field of time-use epidemiology: definitions, concepts, statistical methods, theoretical framework, and future directions. Kinesiology. 2017;49(2).
42. Lin Y, Tremblay MS, Katzmarzyk PT, Fogelholm M, Hu G, Lambert E V, et al. Temporal and bi-directional associations between sleep duration and physical activity/sedentary time in children: An international comparison. Prev Med (Baltim). 2018;111:436-41.

43. Rhodes RE, Stearns J, Berry T, Faulkner G, Latimer-Cheung AE, O'Reilly N, et al. Predicting parental support and parental perceptions of child and youth movement behaviors. Psychol Sport Exerc. 2019;41:80-90.

44. Tashjian SM, Mullins JL, Galván A. Bedtime autonomy and cellphone use influence sleep duration in adolescents. J Adolesc Health. 2019:64(1):124-30.

45. Pearson N, Griffiths P, Biddle SJH, Johnston JP, McGeorge S, Haycraft E. Clustering and correlates of screen-time and eating behaviours among young adolescents. BMC Public Health. 2017;17(1):533.

46. Christensen CG, Bickham D, Ross CS, Rich M. Multitasking with television among adolescents. J Broadcast Electron Media. 2015 Jan 2;59(1):130-48.

47. Katapally TR, Chu LM. Methodology to derive objective screen-state from smartphones: a SMART platform study. Int J Environ Res Public Health. 2019; 16(13):2275.

48. Park KS, Lee D-H, Lee J, Kim YJ, Jung KY, Kim KM, et al. Comparison between two methods of bioelectrical impedance analyses for accuracy in measuring abdominal visceral fat area. J Diabetes Complicat. 2016;30(2):343-9.

\section{Publisher's Note}

Springer Nature remains neutral with regard to jurisdictional claims in published maps and institutional affiliations.

\section{Ready to submit your research? Choose BMC and benefit from:}

- fast, convenient online submission

- thorough peer review by experienced researchers in your field

- rapid publication on acceptance

- support for research data, including large and complex data types

- gold Open Access which fosters wider collaboration and increased citations

- maximum visibility for your research: over $100 \mathrm{M}$ website views per year

At BMC, research is always in progress.

Learn more biomedcentral.com/submissions 